\title{
El Hospital Juárez de México y la COVID-19
}

\section{The Hospital Juárez de México and COVID-19}

Gustavo E. Lugo-Zamudio*

Dirección General, Hospital Juárez de México, Ciudad de México, México
Desde finales del siglo XX se han acentuado algunos factores epidemiológicos, que se identifican como elementos que favorecen la aparición de enfermedades infecciosas emergentes con impacto en la salud pública. La emergencia y reemergencia de enfermedades es un fenómeno global que requiere vigilancia epidemiológica constante, designación de recursos y contar con una organización de los sistemas de salud que aseguren el alertar de manera temprana ante cualquier evento de esta naturaleza, para detonar acciones de control, mitigación o, en el mejor de los escenarios, eliminación del riesgo sanitario.

La emergencia sanitaria provocada por la enfermedad por coronavirus 2019 (COVID-19) hoy reta a la humanidad en todos los frentes imaginables. Si bien el sector en primera línea ha sido y es el sector salud, es claro que todas las actividades productivas, educativas, sociales y culturales, por mencionar algunas más, se han comprometido e inciden en la estabilidad y supervivencia del ser humano.

El Hospital Juárez de México, arraigado en el sector salud y con más de 173 años de historia, es una institución que ha sido y es actor de la vida nacional; hoy sumado al esfuerzo de control y mitigación de la pandemia con acciones directas en la primera línea, designado desde el inicio de la conformación del frente común del sector, hospital COVID-19, ha establecido un modelo de reconversión hospitalaria que ha permitido dar respuesta a la necesidad de atención de la emergencia sanitaria, logrando además, dar continuidad de servicios a enfermedades crónicas no transmisibles, conservando áreas funcionales e independientes para pacientes sin patología COVID-19, lo que operativamente estableció un sistema de atención mixto.

El Hospital Juárez de México es una institución pública formada por mujeres y hombres que, hoy como ayer, refrendan su compromiso con quien requiere atención para recuperar o controlar su salud, con la conformación del recurso humano de excelencia, que inserta la innovación como estrategia en la mejora continua, participando activamente en la implementación del nuevo modelo de universalidad y gratuidad de los servicios médicos.

El trasmitir y conservar el conocimiento escrito es un matiz adicional de las grandes instituciones. Agradezco la oportunidad de contribuir en este espacio académico literario del Hospital Juárez de México.

\section{Correspondencia:}

*Gustavo E. Lugo-Zamudio

E-mail: zalugusta1@gmail.com
Fecha de recepción: 01-02-2021

Fecha de aceptación: 08-02-2021

DOI: 10.24875/RHJM.M21000012
Disponible en internet: 09-04-2021

Rev Hosp Jua Mex. 2021;88(1):1

www.revistahospitaljuarez.com licencia CC BY-NC-ND (http://creativecommons.org/licenses/by-nc-nd/4.0/). 